\title{
Blendas Poliméricas Biodegradáveis de PHB e PLA para Fabricação de Filmes
}

\author{
Wagner Mauricio Pachekoski \\ Empresa Brasileira de Pesquisa Agropecuária - Embrapa/CNPDIA \\ Carla Dalmolin \\ Departamento de Química, Universidade do Estado de Santa Catarina - UDESC \\ José Augusto Marcondes Agnelli \\ Departamento de Materiais, Universidade Federal de São Carlos - UFSCar
}

\begin{abstract}
Resumo: O poli(hidroxibutirato) - PHB - e o poli(ácido lático) - PLA - são dois poliésteres termoplásticos com grande potencial para uso em aplicações industriais, sendo viáveis nos principais métodos de processamento e totalmente biodegradáveis. Porém, devido às suas propriedades mecânicas limitadas, necessitam de modificações para melhorar seu desempenho e tornarem-se industrialmente competitivos. Foram estudadas propriedades e características destes dois polímeros e suas misturas poliméricas, avaliando a possibilidade do uso na preparação de filmes finos por extrusão para embalagens. Verificou-se a possibilidade de produção de filmes finos de misturas PHB/PLA, através das técnicas de extrusão de filmes, planos e tubulares soprados. Porém, para viabilizar a produção industrial destes filmes, modificações devem ser realizadas no processo de produção e/ou no preparo da mistura polimérica através da aditivação, com o objetivo de reduzir a alta adesividade dos filmes durante o seu processamento.
\end{abstract}

Palavras-chave: Blendas, filmes biodegradáveis, polímero biodegradável.

\section{Biodegradable Polymeric Blends of PHB and PLA for Film Production}

Abstract: Poly(hydroxybutyrate) - PHB - and poly(latic acid) - PLA - are thermoplastic polyesters with huge potential for industrial applications since they are fully biodegradable and can be processed by usual methods. However, due to their limited mechanical properties, they need to be modified to achieve better performance and become industrially competitive. The properties of both polymers and their mixtures were evaluated in order to investigate their application for thin films extrusion, for packages. PHB/PLA thin films were produced by extrusion and blow film techniques. To allow for an industrial production process, the preparation of the polymer blend should be changed in order to decrease their high adhesion during processing.

Keywords: Blends, biodegradable films, biodegradable polymer.

\section{Introdução}

Segundo a norma para terminologias da American Society for Testing and Materials ASTM D-883 ${ }^{[1]}$, polímeros biodegradáveis são definidos como um plástico degradável, em que a degradação é resultado da ação de microorganismos de ocorrência natural, como bactérias, fungos e algas. Inicialmente, estes materiais foram desenvolvidos para o uso no campo cirúrgico e médico em geral, que exigem propriedades como compatibilidade orgânica, dissolução no interior do organismo ou capacidade de absorção, assim como propriedades mecânicas apropriadas que possibilitassem o uso destes materiais como reforço/complementação de estruturas orgânicas faltantes, fios de sutura ou acondicionamento de fármacos (drágeas) ${ }^{[2,3]}$. A percepção que tais propriedades poderiam ser aproveitadas em áreas tão distintas como a de embalagens, tecidos e tintas resultou num expressivo aumento dos estudos tecnológicos desta classe de materiais, resultando em significativos avanços através da descoberta de novos materiais, da identificação de processos de degradação e novos métodos de preparo ${ }^{[4,5]}$.

Os principais polímeros biodegradáveis são os derivados do amido e dos poliésteres baseados nos ácidos hidroxi-carbônicos. Os produtos derivados de amido são atrativos devido ao baixo custo, enquanto os poliésteres são de interesse pelo fato de serem produzidos por fermentação ou rotas sintéticas acessíveis ${ }^{[6,7]}$. Entre os poliésteres biodegradáveis conhecidos, destacam-se o poli(hidroxibutirato) - PHB - e o poli(ácido lático) - PLA ${ }^{[8]}$.

O PHB é um polímero oticamente ativo do $\mathrm{D}(-)$ 3 - ácido hidroxibutírico. Sua produção em grande escala acontece por um processo de fermentação bacterial: bactérias como a Alcaligenes eutrophus, produzem até $90 \%$ do seu peso seco de PHB, de cristalinidade superior a $80 \%$ e massa molar em torno de $400.000 \mathrm{~g} / \mathrm{mol}^{[9,10]}$. O PHB é um polímero com boa biocompatibilidade, evidenciada indiretamente pelas

Autor para correspondência: Wagner Mauricio Pachekoski, Embrapa Instrumentação Agropecuária - EMBRAPA/CNPDIA,

R. XV de novembro 1452, Centro, CEP 13560-970, São Carlos, SP, Brasil, e-mail: wagner.pachekoski@gmail.com 
suas potenciais aplicações biomédicas, como em fios de suturas cirúrgicas, próteses e proteções para lesões na pele ${ }^{[3,11]}$. As propriedades mecânicas são semelhantes as do polipropileno, porém, devido a sua alta cristalinidade, o PHB é rígido e frágil, o que torna o seu uso limitado ${ }^{[12-15]}$.

O PLA foi descoberto em 1932 por Carothers, que produziu um produto de baixo valor de massa molar pelo aquecimento sob vácuo do ácido lático ${ }^{[16]}$. Testes em escala comercial confirmam a facilidade de processamento do material, que acontece em temperaturas próximas das poliolefinas (aproximadamente $220^{\circ} \mathrm{C}$ ), resultando em produtos finais com propriedades similares as dos poliésteres ${ }^{[17]}$. O PLA é amplamente estudado para aplicações medico-sirúrgicas, ${ }^{[6,18]}$ e atualmente um dos principais polímeros biodegradáveis utilizados comercialmente, tendo uma variedade de usos que como garrafas para água mineral e fios e fibras para tecidos ${ }^{[19]}$.

Vários autores estudaram o comportamento térmico e a miscibilidade de misturas poliméricas de poli(hidroxibutirato) e poli(ácido lático) $)^{[20-24]}$. Tais amostras foram usadas na forma de filmes e preparadas através da codissolução em clorofórmio, sendo verificada em todos os casos a imiscibilidade dos polímeros em todas as composições. As transições térmicas e a temperatura de cristalização dos polímeros puros não são afetadas nas misturas, independente da composição. Tais resultados são relevantes, porém, como demonstrado por Pachekoski ${ }^{[25]}$ e colaboradores para o poli(hidroxibutirato), o estudo de blendas preparadas através de codissolução não contempla fatores (como temperaturas próximas a degradação térmica do polímero, reações secundárias e cisalhamento) que o preparo de blendas através da fusão via processamento em extrusora e injetora pode propiciar.

Desta maneira, visando aprimorar as propriedades mecânicas do poli(hidroxibutirato) e com o objetivo de possibilitar o uso deste polímero biodegradável na produção de filmes finos, estudou-se neste trabalho o processamento do poli(hidroxibutirato com o poli(ácido lático) e misturas poliméricas nas proporções PHB/PLA (75/25), (50/50) e (25/75). Estas blendas poliméricas foram ainda caracterizadas de maneira a dar um melhor entendimento no mecanismo de mistura destes polímeros e aprimorar as suas propriedades.

\section{Material e Métodos}

Para a realização deste estudo foram preparadas amostras de blendas biodegradáveis utilizando o PHB, fornecido pela PHB Industrial S/A (lote FE 60-3) e PLA, fornecido pela Cargill-Dow (Nature Works 2002D). Foram estudadas diferentes composições nas proporções (massa / massa): $75 \%$ de PHB e $25 \%$ de PLA (75/25), $50 \%$ de PHB e $50 \%$ de PLA $(50 / 50)$, e $25 \%$ de PHB e $75 \%$ de PLA $(25 / 75)$.

\section{Processamento dos materiais}

Tanto o PHB como o PLA foram inicialmente secos em estufa com circulação de ar Soc. Fabbe (modelo 170), a $40{ }^{\circ} \mathrm{C}$ por $4 \mathrm{~h}$, a fim de amenizar a degradação hidrolítica destes materiais durante o processamento ${ }^{[11]}$. As misturas foram preparadas por co-alimentação em extrusora onde polímeros eram adicionados simultaneamente por alimentadores automáticos, com taxas de alimentação que variavam segundo a mistura desejada. Ainda que a taxa de alimentação para cada polímero variasse de acordo com a mistura, a vazão de saída para cada material foi mantida constante em $6 \mathrm{Kg} / \mathrm{h}$. O PHB puro, PLA puro, e as respectivas misturas destes dois componentes foram processadas em extrusora modular, de dupla rosca, co-rotativa Werner \& Pfleiderer ZSK 30 (diâmetro $\mathrm{D}=30 \mathrm{~mm} \mathrm{e}(\mathrm{L} / \mathrm{D})=35)$. Estes materiais foram processados em um perfil de rosca de moderado cisalhamento, para evitar degradação ${ }^{[26]}$

Depois de granulados, os materiais extrudados foram secos e mantidos em estufa com circulação a ar, numa temperatura de $30^{\circ} \mathrm{C}$, até a injeção. Os materiais foram injetados em uma Injetora Arburg All Rounder modelo 270V 300-120 com molde para injeção de corpos de prova ASTM de tração e impacto. Todos os corpos de prova injetados dos diferentes materiais, foram reservados por um tempo mínimo de 7 dias para completa cristalização e posterior realização dos ensaios.

Foram preparados filmes planos e soprados das diferentes composições de blendas de PHB e PLA. Os filmes foram soprados em máquina de sopro com balão descendente e resfriamento com água. A produção de filmes planos por extrusão foi realizada em extrusora de rosca simples $(\mathrm{L} / \mathrm{D}=24)$ Gerst $-25 \mathrm{X} 24-\mathrm{D}$ série $\mathrm{G}$, de matriz plana com sistema de puxamento/enrolamento acoplado. Testes de extrusão de filmes soprados em máquina de sopro com balão ascendente não foram possíveis de serem realizados devido à instabilidade do balão.

\section{Ensaios mecânicos}

Os ensaios mecânicos de tração foram realizados em Máquina universal de ensaios Instron 5500R com célula de carga de $50 \mathrm{KJ}$, extensômetro com registro do módulo elástico a $0,8 \%$ de deformação, uma distância entre garras $\left(1_{0}\right)$ igual a $100 \mathrm{~mm}$ e com uma velocidade de $5 \mathrm{~mm} / \mathrm{min}$ em corpos de prova com dimensões e procedimento de análise especificados na Norma ASTM D-638, sendo os resultados obtidos da média de 7 valores amostrais. Os mesmos testes foram repetidos para corpos de prova após dois anos de envelhecimento e para filmes planos da mistura PHB/PLA (75/25).

Corpos de prova entalhados foram testados em aparelho de resistência ao impacto Izod com entalhe Ceast code 6545100 com um martelo de $2 \mathrm{~J}$, temperatura controlada e segundo norma ASTM D-256. O valor de resistência foi obtido da média dos resultados de 10 amostras avaliadas por este método.

\section{Ensaios de biodegradação}

Foram realizados ensaios de biodegradação para o PHB puro, PLA puro, e as blendas PHB/PLA de diferentes composições através do descarte ao ar livre, simulando a sua degradação ocasionada pelo meio ambiente e intempéries. Para facilitar as medições de perda de massa ao longo do tempo de degradação, nestes testes foram utilizados pedaços dos galhos de injeção com dimensão de $10 \mathrm{~cm}$ e peso de $5 \mathrm{~g}$ para todas as amostras. 
Desta maneira, foram enterradas seis grupos de amostras, contendo em cada grupo uma amostra de PHB, PLA, PHB/PLA (75,25), (50/50) e (25/75), sujeitas aos efeitos climáticos e demais interações com o meio circundante. Mensalmente, cada grupo de amostra foi retirado, com análise do aspecto visual (através de fotos) e da perda de massa.

\section{Resultados e Discussões}

\section{Processamento dos materiais}

O PHB extrudado apresentou um significativo escurecimento, passando de uma cor amarelada para um castanho escuro, resultado de resíduos bacteriais ou de solventes de extração ${ }^{[25]}$, somado ao processo termodegradativo aceleradopelatensãodecisalhamento ${ }^{[26]}$. Por outro lado, o PLA extrudado apresentou-se como um material transparente e de cor amarelada no final do processo, refletindo uma baixa taxa de cristalização e degradação térmica, respectivamente. Observou-se que o PLA possui uma melhor processabilidade que o PHB, de modo que as variações nas condições deste biopolímero não inviabilizaram o seu processamento.

De maneira geral, foram produzidos materiais homogêneos, sendo que as blendas apresentaram uma coloração castanha, semelhante ao PHB puro, mas com uma intensidade menor a medida que a proporção de PHB na mistura diminui, conforme pode ser verificado mais adiante, quando serão discutidos os ensaios de biodegradação. Quanto ao processamento, observou-se que, quanto maior a quantidade de PLA na mistura, maior a capacidade do sistema em suportar pequenas variações no processo sem impedir o processamento do material.

Os materiais foram injetados satisfatoriamente, produzindo corpos de prova homogêneos e com excelente acabamento superficial. Como processos secundários de cristalização se prolongaram por aproximadamente 2-3 dias após o resfriamento do PHB, alterando suas propriedades físicas ao longo do tempo (fenômeno de envelhecimento) ${ }^{[25,27]}$, aguardou-se pelo menos sete dias para realização dos ensaios mecânicos após a injeção dos corpos de prova.

Foram realizados testes de filmes planos para os polímeros biodegradáveis PHB, PLA e as misturas PHB/PLA (75/25), (50/50) (25/75) a partir dos grânulos extrudados destas misturas. As condições gerais de processamento são apresentadas na Tabela 1, indicando que, para o PHB e o PLA, os parâmetros são muito parecidos, enquanto que as suas misturas possuíram condições intermediárias, ajustadas em função da otimização do processo. Os melhores resultados de processamento foram obtidos para o PLA puro, obtendo-se um filme de alta estabilidade no puxamento. $\mathrm{O}$ material que apresentou maior dificuldade para o processamento foi o PHB, que ofereceu grande dificuldade para estabilização do puxamento. Esta dificuldade era principalmente ilustrada por uma grande facilidade na fratura do filme antes do completo resfriamento, dificultando o seu estiramento. Para as misturas, esta dificuldade de processamento se tornou proporcional à quantidade de PHB.

Filmes das misturas PHB/PLA 75/25, 50/50 e 25/75 também foram produzidos em máquina de sopro com balão descendente e resfriamento com água. Todos os materiais foram processados nas mesmas condições, conforme apresentadas na Tabela 2. De acordo com os resultados durante o processamento, observou-se a possibilidade de produção de filmes planos por sopro de todas as misturas, com boa estabilidade do balão e elasticidade e homogeneidade do material fundido. Porém, foi observada uma grande adesividade do filme nos roletes de puxamento e sob si próprio. Esta adesividade foi proporcional a quantidade de PHB na mistura e impossibilitou o enrolamento dos filmes relativos as misturas PHB/PLA (75/25) e PHB/PLA (50/50). Esta propriedade parece estar correlacionada com as características intrínsecas de elasticidade do PHB no processamento e desaparecem no resfriamento do filme.

\section{Ensaios mecânicos}

Foram realizados testes de resistência ao impacto e tração para o PHB, PLA e suas misturas PHB/PLA (75/25), (50/50) e (25/75). Os resultados são apresentados na Tabela 3, enquanto a Figura 1 apresenta um gráfico comparativo dos resultados de resistência ao impacto e a Figura 2 apresenta os ensaios de tração para as amostras estudadas.

De acordo com os resultados de resistência ao impacto apresentados na Tabela 3, verifica-se que o PLA apresenta um valor médio 68\% superior ao PHB. Observa-se ainda que as misturas PHB/PLA apresentam valores que não se enquadram dentro deste intervalo de valores, porém, devido a sobreposição de valores dentro da faixa de erros, não foi possível identificar algum tipo de interação entre estes homopolímeros. A mistura PHB/ PLA (75/25) apresentou um valor médio de resistência ao impacto 8\% inferior ao obtido para o PHB. Apesar de estes valores sugerirem um comportamento antagônico desta blenda, estes se situam dentro dos limites do desvio padrão destes materiais, não possibilitando uma discussão mais aprofundada. Para a mistura PHB/PLA

Tabela 1. Condições de processamento em extrusora de filme plano para o PHB, PLA e suas blendas.

\begin{tabular}{|c|c|c|c|c|c|}
\hline \multirow[t]{2}{*}{ Material } & \multirow{2}{*}{$\begin{array}{l}\text { Velocidade de rosca } \\
\text { (rpm) }\end{array}$} & \multirow{2}{*}{$\begin{array}{l}\text { Puxamento } \\
\text { (Volt) }\end{array}$} & \multicolumn{3}{|c|}{ Temperatura $\left({ }^{\circ} \mathbf{C}\right)$} \\
\hline & & & Cabeçote & Barril & Funil \\
\hline PHB & 24 & 33 & 179 & 180 & 160 \\
\hline PLA & 24 & 25 & 180 & 185 & 161 \\
\hline PHB/PLA (75/25) & 24 & 33 & 179 & 180 & 160 \\
\hline PHB/PLA (50/50) & 24 & 30 & 179 & 183 & 160 \\
\hline PHB/PLA (25/75) & 24 & 27 & 180 & 185 & 161 \\
\hline
\end{tabular}


(50/50) encontrou-se um resultado próximo a média aritmética dos valores encontrados para o PHB e o PLA. Considerando-se a regra das misturas, este valor encontra-se muito próximo ao esperado $(32,5 \mathrm{~J} / \mathrm{m})$ para um blenda que se comporte de acordo com esta situação e não apresente interação dos seus componentes. Na mistura PHB/PLA (25/75), o valor médio de resistência ao impacto é $12 \%$ maior que o valor médio encontrado para o PLA, sugerindo uma interação sinérgica nesta blenda. Porém, assim como na mistura PHB/PLA (25/75), existe uma sobreposição de desvios padrões, impossibilitando uma análise precisa destes resultados.

A Figura 2 mostra os resultados dos ensaios de tração. Observa-se o caráter rígido e frágil do PHB, caracterizado pela baixa deformação do material, sua repentina ruptura e alto módulo elástico. Estas propriedades são associadas a alta cristalização deste polímero ${ }^{[17]}$. A fragilização do PHB, porém, pode se prolongar durante certo tempo após a sua completa cristalização (cerca de 3 dias). Este fenômeno, denominado "envelhecimento do PHB", não foi até o momento claramente explicado, sendo atribuído a cristalizações secundárias na matriz polimérica ${ }^{[18]}$.

O PLA apresenta, assim como PHB, um comportamento rígido e frágil. Porém, a maior deformação e a ruptura gradual indicam menor fragilidade, enquanto o maior módulo indica maior rigidez. Ainda de acordo com a Figura 2, observa-se que os aumentos na tensão, no módulo e na deformação nas misturas PHB/PLA são proporcionais à porcentagem de PLA na composição, indicando uma redução na fragilidade da mistura (fragilidade atribuída ao PHB), proporcional a quantidade de PLA na sua composição. As misturas PHB/PLA (75/25) e (50/50) apresentam valores de deformação máxima e deformação na ruptura similares ao $\mathrm{PHB}$, indicando a não existência de uma interação entre os polímeros. Já para a mistura PHB/PLA (25/75), novamente verifica-se um efeito sinérgico nos valores médios de deformação, sugerindo que nesta mistura ocorre algum efeito do tipo transesterificação. Segundo a Tabela 3, as misturas (PHB/PLA) também apresentam um aumento no módulo proporcional a porcentagem de PLA na formulação, indicando um aumento na rigidez. Porém, uma sobreposição dos desvios padrões das médias destes valores impossibilita maiores conclusões.

Tabela 2. Condições de processamento de sopro para os filmes de PHB/PLA

\begin{tabular}{ccccccc}
\hline \multirow{2}{*}{$\begin{array}{c}\text { Rotação } \\
(\mathbf{r p m})\end{array}$} & $\mathbf{7 1}$ & $\mathbf{Z 2}$ & $\mathbf{Z 3}$ & $\mathbf{Z 4}$ & Cabeçote & Fundido \\
\cline { 2 - 7 } & 150 & 157 & 175 & 180 & 182 & 185 \\
\hline 35 & 152 &
\end{tabular}

Observou-se uma redução da rigidez com o aumento gradual da tenacidade das blendas de PHB e PLA proporcional a quantidade de PLA na mistura, sendo que a mistura PHB/PLA (25/75) e o PLA puro apresentam a mesma tenacidade.

Com o objetivo de avaliar o tempo de envelhecimento sobre os corpos de prova do PHB, PLA e suas misturas, os ensaios de tração foram repetidos após dois anos de estocagem dos corpos de prova injetados, sob condições de temperatura, umidade e luminosidade controladas, sem qualquer tipo de ataque degradativo posterior. A Figura 2 apresenta um gráfico comparativo entre as amostras envelhecidas e não envelhecidas, e a Tabela 4

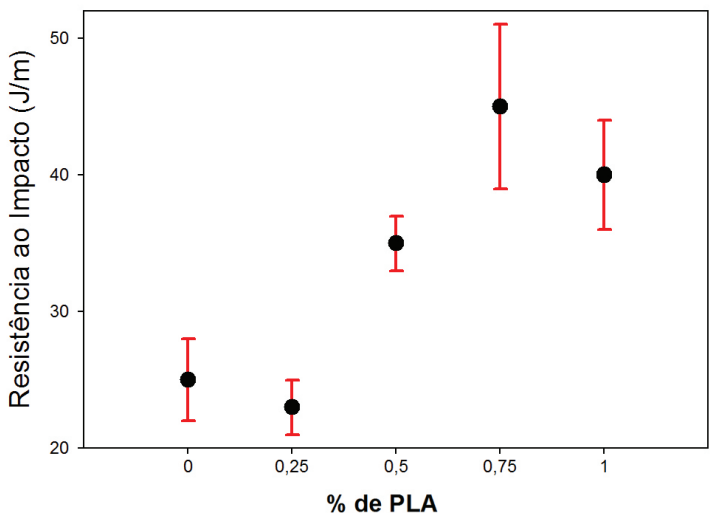

Figura 1. Gráfico comparativo dos valores de resistência ao impacto obtidos para as misturas de PHB/PLA conforme a quantidade de PLA na composição.

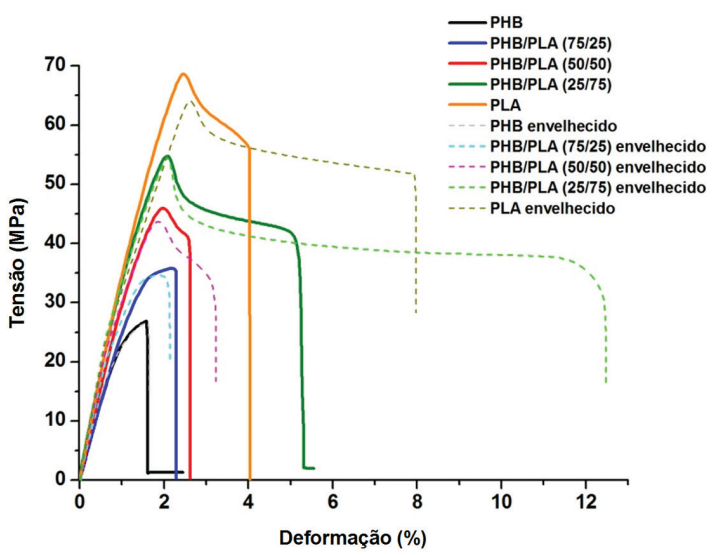

Figura 2. Ensaios de tração comparativos de amostras envelhecidas e não envelhecidas de PHB, PLA e suas misturas.

Tabela 3. Resultado dos ensaios mecânicos realizados para o PHB, PLA e suas misturas

\begin{tabular}{lccccc}
\hline & PHB & PHB/PLA (75/25) & PHB/PLA (50/50) & PHB/PLA (25/75) & PLA \\
\hline Resistência ao Impacto (J/m) & $25 \pm 3$ & $23 \pm 2$ & $35 \pm 2$ & $45 \pm 6$ & $40 \pm 4$ \\
Tensão Máxima (MPa) & $28 \pm 1$ & $40 \pm 1$ & $46 \pm 1$ & $53 \pm 3$ & $58 \pm 1$ \\
Deformação Máxima (\%) & $2,0 \pm 0,5$ & $2,0 \pm 0,1$ & $2,0 \pm 0,1$ & $4,4 \pm 0,1$ & $3,5 \pm 0,5$ \\
Tensão na Ruptura (MPa) & $28 \pm 1$ & $39 \pm 1$ & $46 \pm 1$ & $53 \pm 3$ & $58 \pm 2$ \\
Deformação na Ruptura (\%) & $2,0 \pm 0,1$ & $2,0 \pm 0,1$ & $2,0 \pm 0,1$ & $4,0 \pm 0,1$ & $2,5 \pm 0,1$ \\
Módulo de Elasticidade (GPa) & $3,0 \pm 0,5$ & $3,0 \pm 0,5$ & $3,5 \pm 0,5$ & $4,0 \pm 0,5$ & $4,0 \pm 0,5$ \\
Tenacidade (J/m $\left.{ }^{3}\right)$ & $0,5 \pm 0,1$ & $1,0 \pm 0,05$ & $1,5 \pm 0,1$ & $2,0 \pm 0,1$ & $2,0 \pm 0,1$ \\
\hline
\end{tabular}


Tabela 4. Resultados dos ensaios de tração dos corpos de prova envelhecidos de PHB, PLA e suas misturas.

\begin{tabular}{lccccc}
\hline & PHB & PHB/PLA (75/25) & PHB/PLA (50/50) & PHB/PLA (25/75) & PLA \\
\hline Tensão Máxima (MPa) & $24 \pm 2$ & $31 \pm 2$ & $24 \pm 6$ & $23 \pm 10$ & $47 \pm 1$ \\
Deformação Máxima (\%) & $2,0 \pm 0,1$ & $2,0 \pm 0,3$ & $3,0 \pm 0,3$ & $10,0 \pm 0,4$ & $8,0 \pm 0,8$ \\
Módulo de Elasticidade (GPa) & $2,8 \pm 0,1$ & $3,0 \pm 0,1$ & $3,5 \pm 0,1$ & $4,0 \pm 0,2$ & $3,5 \pm 0,5$ \\
\hline
\end{tabular}

apresenta os resultados destes ensaios, que podem ser comparados com a Tabela 3, referente aos corpos de prova não envelhecidos.

De acordo com estes resultados observa-se claramente que o PHB e o PLA possuem comportamentos distintos no envelhecimento. O PHB não apresenta modificações significativas de propriedades mecânicas durante o envelhecimento, mantendo suas características de rigidez e fragilidade. Por outro lado, PLA apresenta uma redução na sua rigidez com o envelhecimento, verificada por meio da diminuição no valor do módulo elástico e aumento significativo na deformação antes da ruptura. As misturas PHB/PLA também são diretamente influenciadas por estas propriedades, apresentando uma gradual redução na rigidez com o aumento da concentração de PLA. Para a mistura PHB/PLA (25/75) este fenômeno é aparentemente aumentado pelo efeito sinérgico da mistura, apresentando um aumento médio de $100 \%$ na deformação antes da ruptura.

Sabe-se que as propriedades mecânicas do poli(ácido lático) se alteram com o decorrer do tempo, num fenômeno de "envelhecimento" do material ${ }^{[28,29]}$. Este fenômeno ocorre de maneira significativa num período de 2-3 dias após a injeção e se prolonga de maneira pouco intensa por um período indeterminado, estipulado em 2 anos. Este envelhecimento está associado a um fenômeno de cristalizações secundárias que confinariam as regiões amorfas, reduzindo a mobilidade das cadeias poliméricas e aumentando a rigidez e fragilidade do material. Porém, estas características de envelhecimento não correspondem ao encontrado para o PLA em estudo, onde ocorre um significativo aumento na ductilidade deste material.

Foram realizados ensaios de tração para os filmes planos da blenda PHB/PLA (75/25) com $10 \mu \mathrm{m}$ e $30 \mu \mathrm{m}$. A Figura 3 apresenta as curvas dos ensaios de tração / deformação dos dois filmes, enquanto Tabela 5 apresenta os valores das propriedades mecânicas medidas nestes ensaios. Observa-se mudanças significativas nas propriedades mecânicas do filme de PHB/PLA (75/25) com $10 \mu \mathrm{m}$ em relação aos corpos de prova injetados da mesma blenda, com um aumento de $39 \%$ para tensão máxima e de $900 \%$ para a deformação. Estes valores podem estar relacionados com o direcionamento sofrido pelas moléculas durante o estiramento do filme, o que ocasionaria o aumento da resistência. Este mesmo direcionamento aparentemente reduz a cristalização dos filmes, justificando a sua semitransparência (Figura 1) e aumento da máxima deformação. Observa-se ainda que apesar do alto valor médio de deformação máxima, este está contido dentro de um largo intervalo de segurança, indicando uma significativa variação nos resultados individuais. Estas variações podem ser justificadas em possíveis diferenças de direcionamento do filme durante o estiramento.

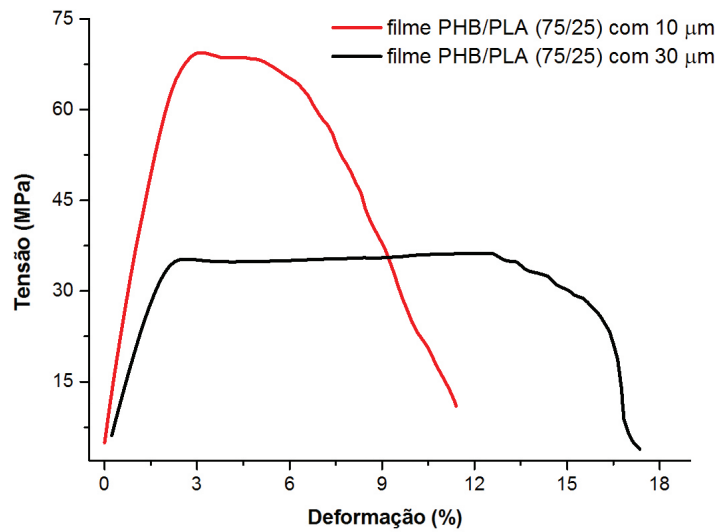

Figura 3. Gráficos dos ensaios de tração dos filmes de PHB/PLA (75/25) com espessuras de $10 \mu \mathrm{m}$ e $30 \mu \mathrm{m}$.

Tabela 5. Resultados dos ensaios de resistência à tração para filmes planos da blenda PHB/PLA (75/25), com diferentes espessuras.

\begin{tabular}{lcc}
\hline Espessura do filme $(\mu \mathrm{m})$ & 10 & 30 \\
Tensão Máxima $(\mathrm{MPa})$ & $64 \pm 5$ & $34 \pm 2$ \\
Deformação Máxima $(\%)$ & $18 \pm 8$ & $17 \pm 3$ \\
Carga Máxima (kgf) & $1,3 \pm 0,1$ & $2,0 \pm 0,1$ \\
Módulo de Elasticidade $(\mathrm{GPa})$ & $3,0 \pm 0,8$ & $2,0 \pm 0,1$ \\
\hline
\end{tabular}

Para os filmes planos de PHB/PLA (75/25) com $30 \mu \mathrm{m}$, um aumento substancial também é verificado para a máxima deformação $(850 \%)$, porém o aumento na espessura aparentemente reduz a fragilidade e rigidez deste filme, reduzindo a sua máxima tensão e módulo de elasticidade. Este fenômeno é claramente observado na comparação das curvas dos ensaios de tração / deformação dos dois filmes, apresentadas na Figura 3. Observa-se que o filme de $10 \mu \mathrm{m}$ apresenta uma característica de ruptura abrupta, característica de um material frágil; para o filme de $30 \mu \mathrm{m}$ observa-se um maior estiramento (deformação plástica) do filme antes da total ruptura, caracterizando um material mais dúctil e tenaz.

\section{Ensaios de biodegradação}

Foram realizados ensaios de biodegradação para o PHB, PLA e as misturas PHB/PLA (75/25), (50/50) e $(25 / 75)$, apresentados na Figura 4. De acordo com estes ensaios, observou-se que num período de 6 meses não ocorreu qualquer variação de massa nas amostras analisadas.

Baseando-se no aspecto visual, observou-se somente no PHB algum tipo de modificação significativa, com o aparecimento de uma película branca na superfície do corpo de prova a partir do segundo mês de ensaio. Aparentemente, esta modificação superficial 


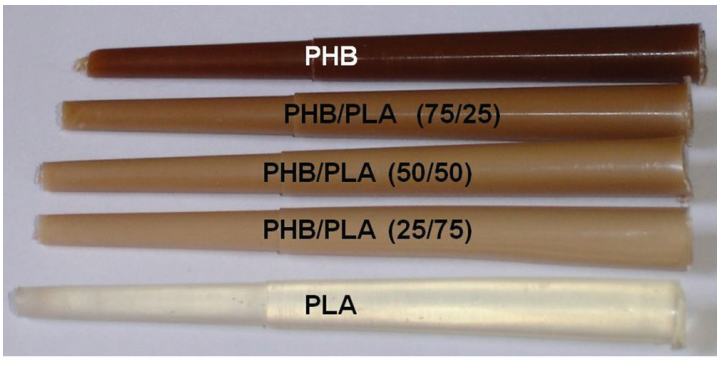

(a)

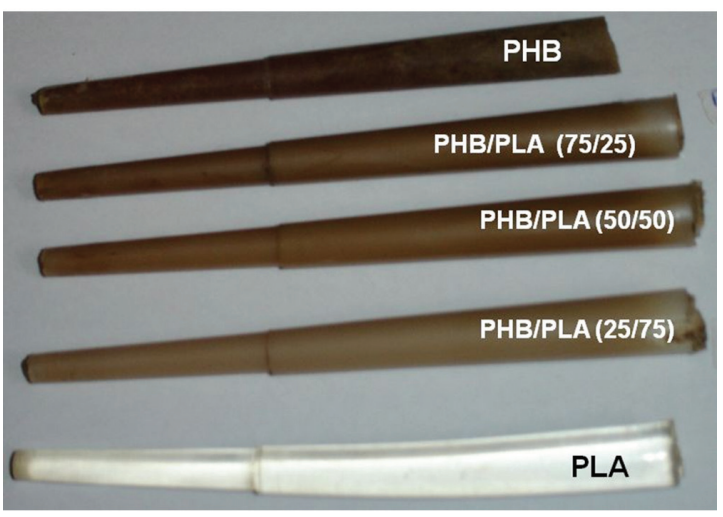

(b)

Figura 4. Corpos de prova de PHB, PLA e suas misturas (a) antes e (b) após 6 meses de ensaio de biodegradação.

é resultante do crescimento de uma colônia de microrganismos (fungos/bactérias) interagindo com o poli(hidroxibutirato). Evidencia-se ainda a biodegradação do PHB com o aumento da rugosidade superficial dos corpos de prova ensaiados. Esta característica concorda com os resultados obtidos por Sharma e sua equipe ${ }^{[30]}$ no estudo da biodegradação do PHB. Estes estudos indicam que a biodegradação se inicia superficialmente, e é caracterizada pelo aumento da rugosidade superficial devido a gradativa erosão superficial do polímero. A não ocorrência de biodegradação aparente no PLA e nas misturas PHB/PLA corrobora com os resultados obtidos por Koyama ${ }^{[31]}$, que determina em 1 ano o tempo mínimo para o início da biodegradação do PLA.

\section{Conclusões}

Foram realizados testes que comprovaram a possibilidade de preparo de filmes finos das misturas PHB/PLA através dos processos de extrusão de filme plano e sopro, em qualquer proporção das misturas PHB/ PLA testadas. Porém, devido às dificuldades obtidas na realização dos mesmos, sugere-se que, para viabilizar a produção industrial destes filmes, devem ser realizadas modificações na mistura polimérica (aditivação com plastificantes e nucleantes de origem natural ${ }^{[32]}$ ) ou no processo de produção para otimizar o resfriamento do polímero, evitando a aderência das paredes do filme no colapso do balão.

$\mathrm{O}$ estudo das propriedades mecânicas das misturas de PHB e PLA sugere que as misturas PHB/PLA (75/25) e PHB/PLA (50/50) seguem a regra das misturas, sendo suas propriedades proporcionais a quantidade dos seus componentes. A mistura PHB/PLA (25/75) apresenta valores médios superiores aos dos homopolímeros, sugerindo algum tipo de sinergismo nesta mistura. Estudos de envelhecimento demonstraram que os polímeros estudados e suas blendas apresentam um aumento na ductibilidade durante um intervalo de tempo de 2 anos, sugerindo a mudança das propriedades físicas destes materiais com o decorrer do tempo.

Estudos de biodegradação no solo in natura, demonstraram que somente o PHB apresenta sinais visuais de biodegradação num período de 6 meses. As misturas PHB/PLA e o PLA puro não apresentaram sinais visuais significativos de biodegradação. Para o mesmo período de tempo não foi detectada nenhuma variação na massa dos corpos de prova, tanto dos homopolímeros como das misturas PHB/PLA.

\section{Agradecimentos}

Os autores agradecem à PHB Industrial e à CargillDow pelo fornecimento dos polímeros, e ao $\mathrm{CNPq}$ e CAPES pelo auxílio financeiro.

\section{Referências Bibliográficas}

1. Annual Book of ASTM Standards. - "Terminology relating to plastics", D883, vol. 08.01.

2. Zhang, L.; Xiong, C. \& Deng, X. - J. Appl. Pol. Sci., 56, p.103 (1995). http://dx.doi.org/10.1002/app.1995.070560114

3. Domb, A. J. \& Kumar, N. - "Biodegradable Polymers in Clinical Use and Clinical Development”, Wiley (2011). http://dx.doi.org/10.1002/9781118015810

4. Mallapragada, S. \& Narasimham, B. - "Handbook of Biodegradable Polymeric Materials and Their Applications", Wiley-WCH (2006).

5. Rosário, F.; Pachekoski, W. M.; Silveira, A. P. J.; Santos, S. F. \& Casarin, S. A. - Polímeros, 21, p.90 (2011). http:// dx.doi.org/10.1590/S0104-14282011005000021

6. Bemiller, J. \& Whistler, R. - "Starch: chemistry and technology", 3th ed., Elsevier (2010).

7. Pelicano, M.; Pachekoski, W. M. \& Agnelli, J. A. M. - Polímeros, 19, p.212 (2009).

8. Casarin, S. A.; Agnelli, J. A. M.; Malmonge, S. M. \& Rosário, F. - Polímeros, 23, p.115 (2013).

9. Schegel, H. G.; Grottschalk, G. \& Von Bartha, R. - Nature, 191, p.463 (1961).

10. Chen, G. - "Plastics from Bacteria Natural Functions and Applications (Microbiology Monographs Volume 14)", Springer-Verlag, Berlin Heidelberg (2010).

11. Griffith, L. G. - Acta Mater., 48, p.263 (2000). http://dx.doi. org/10.1016/S1359-6454(99)00299-2

12. Howel, E. R. - Chem. Ind., p.508 (1982).

13. Pachekoski, W. M.; Agnelli, J. A. M. \& Belem, L. P. - Mater. Res., 12, p.159 (2009). http://dx.doi.org/10.1590/S151614392009000200008

14. Koning, G. J. M. - "Prospects Of Bacterial Poly[(R)-3Hydroxyalkanoates]", Technische Universiteit Eindhoven, Holanda (1993).

15. Platt, D. K. - "Biodegradable Polymers: Market Report", Wiley (2011). 
16. Garlota, D. - J. Pol. Env., 9, p.61 (2001).

17. Ren, J. - "Biodegradable Poly(Lactic Acid): Synthesis, Modification, Processing and Application", Springer (2011). http://dx.doi.org/10.1007/978-3-642-17596-1

18. Scott, G. \& Gillead, D. - "Degradable Polymers", Chapman \& Hall, London (1995). http://dx.doi.org/10.1007/978-94011-0571-2

19. Auras, R. A.; Lim, L.; Selke, S. E. M. \& Tjudi, H. - "Poly(Lactic Acid): Synthesis, Structures, Properties, Processing, And Applications", Wiley Series On Polymer Engineering And Technology), Wiley (2010). http://dx.doi. org/10.1002/9780470649848

20. Zhang, L.; Xiong, C. \& Deng, X. - Polymer, 37, p.235 (1996). http://dx.doi.org/10.1016/0032-3861(96)81093-7

21. Koyama, N. \& Doi, Y. - Polymer, 38, p.1589 (1997). http:// dx.doi.org/10.1016/S0032-3861(96)00685-4

22. Ohkoshi, I.; Abe, H. \& Doi, Y. - Polymer, 41, p.5989 (2000).

23. Blüm, E. \& Owen, A. J. - Polymer, 36, p.4077 (1995). http://dx.doi.org/10.1016/0032-3861(95)90987-D

24. Vanin, M.; Santana, C. C.; Torriani, Í. L., Privelic, T. \& Duek, E. A. R.- Polímeros, 14, p.187 (2004). http://dx.doi. org/10.1590/S0104-14282004000300015
25. Aref-Azar, A. A.; Biddlestone, F., Hay, J. N. \& Haward, R. N. - Polymer, 24, p.1245 (1983). http://dx.doi. org/10.1016/0032-3861(83)90053-8

26. Pachekoski, W. M.; Dalmolin, C. \& Agnelli, J. A. M. - Mater. Res., 16, p.327 (2013).

27. Biddlestone, F.; Harris, A. \& Hay, J. N. - Pol. Int., 39, p.221 (1996)

28. Cai, H. \& Dave, V. - J. Pol. Sci.: Pol. Phys., 40, p.2701 (1996)

29. Wang, L. - Pol. Deg. Stab., 59, p.161 (1998). http://dx.doi. org/10.1016/S0141-3910(97)00196-1

30. Sharma, R. \& Ray, A. R. - Rev. Macromol Chem. Phys., C35, p.327 (1995). http://dx.doi. org/10.1080/15321799508009640

31. Koyama, N. \& Doi, Y. - Can. J. Microbiol., 41, p.316 (1995). PMid:7606667. http://dx.doi.org/10.1139/m95-203

32. Brunel, D. G.; Pachekoski, W. M.; Dalmolin, C. \& Agnelli, J. A. M. - Mater. Res. In Press.

Enviado: Ago. 2, 2013

Reenviado: Jan. 27, 2014

Aceito: Mar. 13, 2014 